Research Article

\title{
Structural Model of Students' Interest and Self-Motivation to Learning Mathematics
}

\author{
Dominic Otoo, ${ }^{1}$ Wahab A. Iddrisu $\mathbb{D}^{1},{ }^{1}$ Justice A. Kessie $\left(\mathbb{D},{ }^{1}\right.$ and Ernest Larbi ${ }^{2}$ \\ ${ }^{1}$ Department of Mathematics and Statistics, University of Energy and Natural Resources, Sunyani BS-0061-3374, Ghana \\ ${ }^{2}$ Department of Mathematics, Catholic University College of Ghana, Sunyani BY-0622-3666, Ghana \\ Correspondence should be addressed to Justice A. Kessie; justicekessie@gmail.com
}

Received 18 June 2018; Revised 25 September 2018; Accepted 5 November 2018; Published 2 December 2018

Academic Editor: Yi-Shun Wang

Copyright (C) 2018 Dominic Otoo et al. This is an open access article distributed under the Creative Commons Attribution License, which permits unrestricted use, distribution, and reproduction in any medium, provided the original work is properly cited.

Students pick up the perception that mathematics is abstract and therefore, the learning of mathematics would yield to them no benefit. With their attitude towards mathematics modelled and their interest for mathematics impacted by this automatic generated perception, they may never again appreciate the beauty of mathematics. In this paper, the researchers used structural equation modeling (SEM), to investigate the variables that affect students' interest, among the variables, students' confidence and motivation. The foregoing variables were conceptualized to have a direct effect on students' interest in mathematics, whilst mathematics anxiety and students' knowledge of the usefulness of mathematics were conceptualized to have indirect effects on their interest in mathematics moderated by students' confidence and motivation. The result showed that significantly students' confidence directly affects students' interest in the learning of mathematics and there is a direct relationship between confidence and motivation. A student's knowledge about the usefulness of mathematics indirectly increases the student's interest in mathematics.

\section{Introduction}

"The absence of academic motivation and lack of interest is also likely to be reflected in students' neglect of their studies. Research over the last two decades has indicated that adolescents' academic motivation declines over time. Recent studies show that as children get older, their interests and attitudes toward school in general and toward specific subject areas such as mathematics, art, and science tend to deteriorate (Hidi and Harackiewicz [1]).”

Informally, interest is defined in Collins Dictionary as "[2] something that interests you and attracts your attention so that you want to learn or hear more about it or continue doing it." Self-motivation can also be defined as the "[2] motivation arising from an individual's internal desires for the satisfaction and fulfillment of specific needs." In this paper, we seek to investigate the effect of a student's interest and self-motivation on his learning and understanding of mathematics. This is relevant because if indeed the gross self- concept of a student influences his or her performance in mathematics or any subject area, educationists and stakeholders would want to channel their strength in motivating students to have a good self-concept about themselves, especially in Ghana, a country where student's performance in mathematics is on the decline.

A questionnaire circulated by Math Lib and Lab in Ghana (2015) showed that most students and pupils in this population think that mathematics is difficult and they lacked interest and personal motivation for mathematics. Let us think upon these; could it be that the mathematics instructors around these individuals are not good in mathematics or that these mathematics instructors have not known how well to guide their students in patience, so that the total impression made by these mathematics instructors is deadening? Are there those today who will not come to appreciate the beauty of mathematics because it was their peculiar misfortune to at a critical point in their lives come into contact with a deadening mathematics teacher and have 

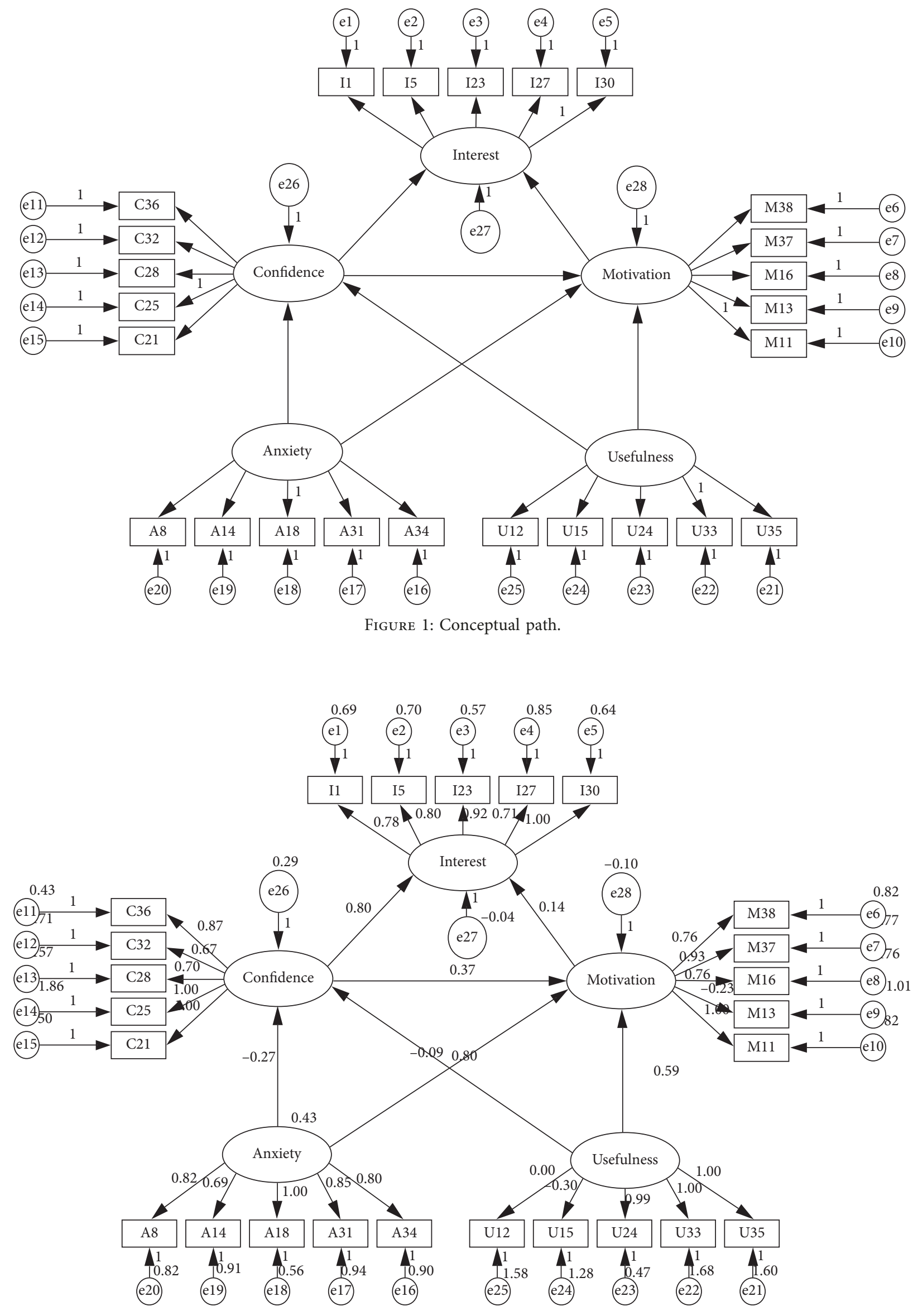

FIgURe 2: Analysed conceptual path. 


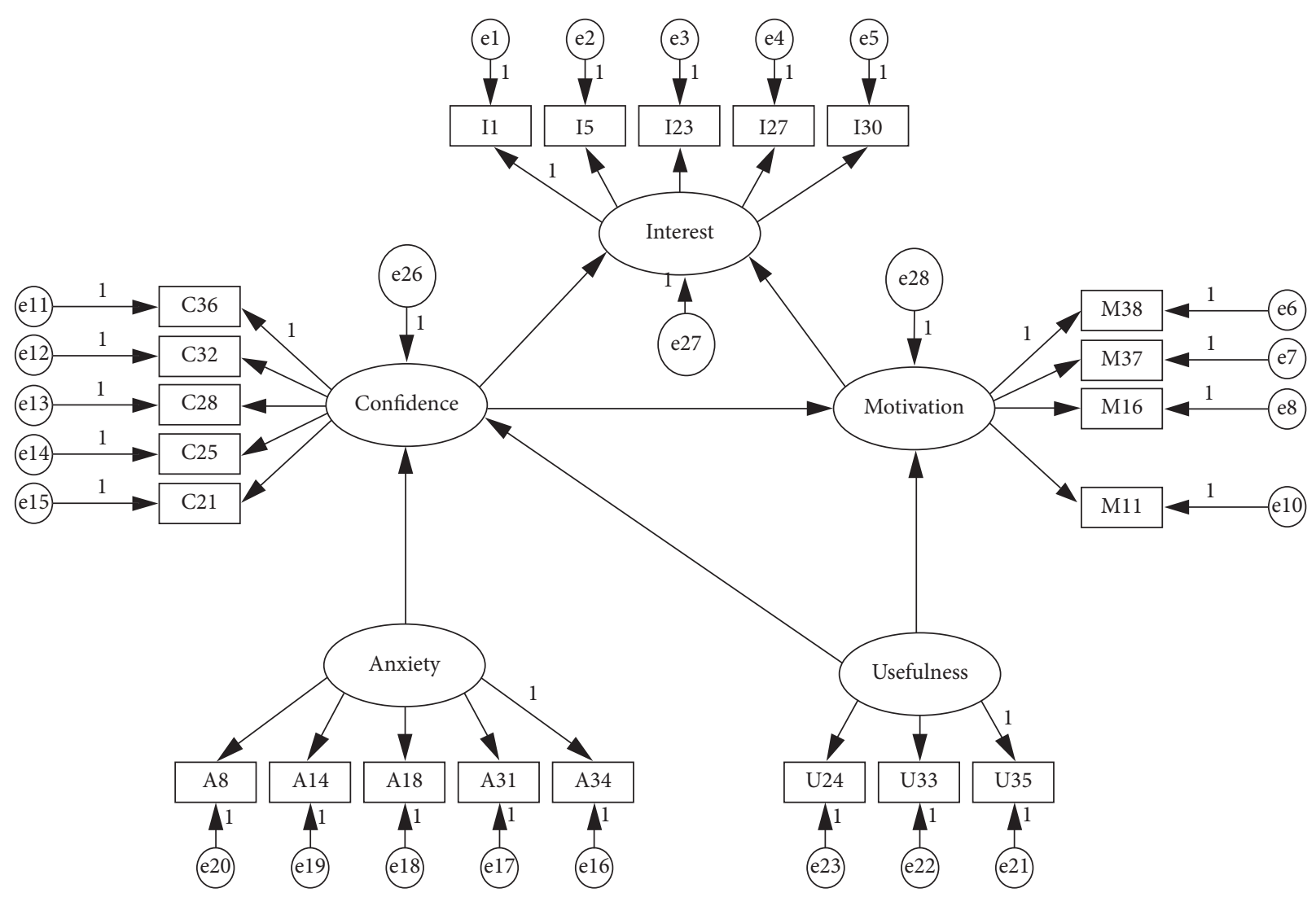

Figure 3: Modified path.

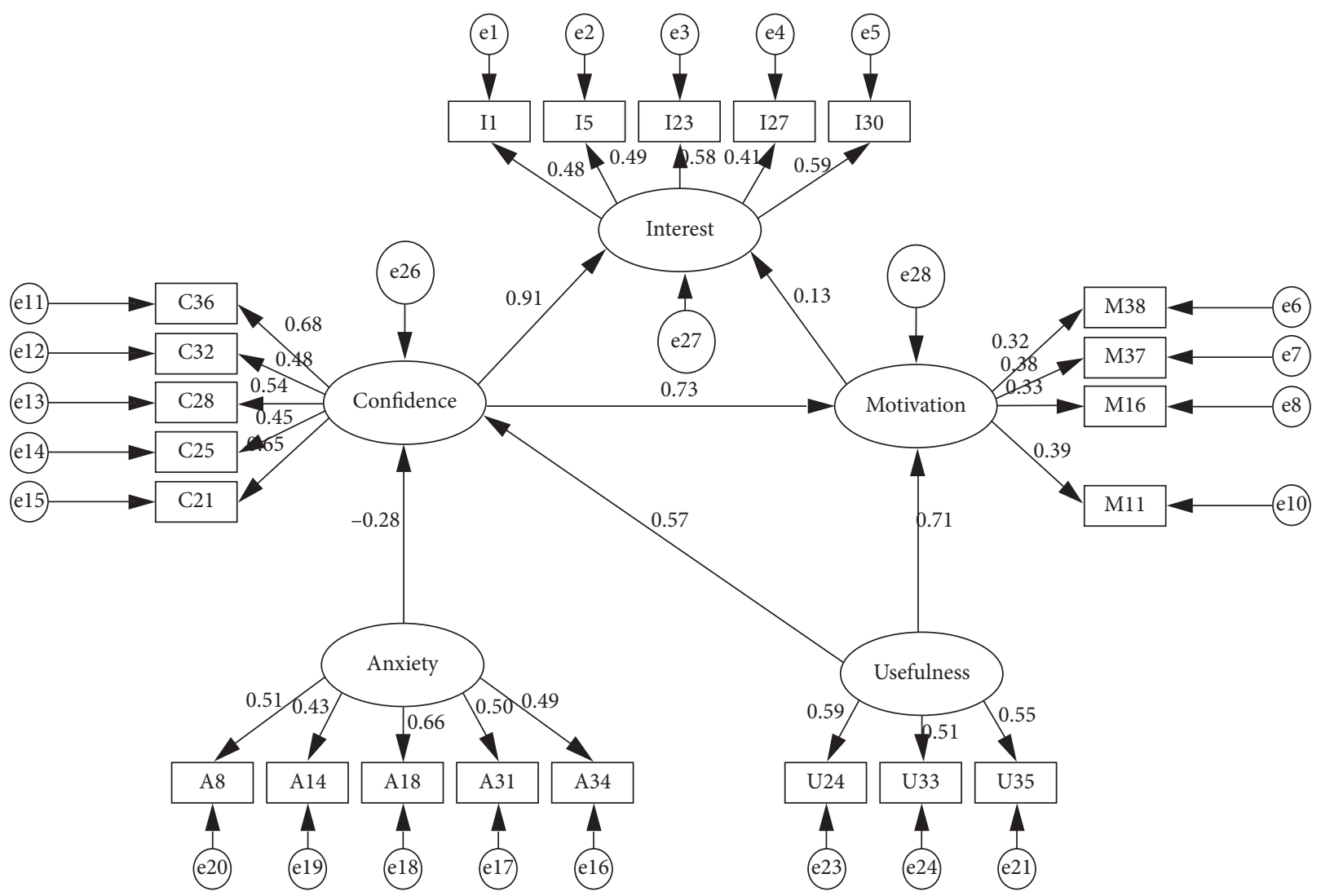

Figure 4: Analysed modified path. 
lost all interest in the study of mathematics? Or, how much difference do students' interest and self-motivation make to the learning of mathematics?

In this paper, students' confidence and motivation were conceptualized to have a direct effect on their interest in mathematics. Anxiety and usefulness of mathematics were conceptualized to have indirect effects on their interest in mathematics, moderated by confidence and motivation. Although significant research has been conducted to identify the factors that influence students' interest and selfmotivation for learning mathematics, the variables such as confidence, motivation, math anxiety, and usefulness conceptualized in this were not thoroughly examined. It is also important to add that no research like this has been done in Ghana.

1.1. Literature Review. Musso et al. [3] in their paper investigated how different but interrelated variables such as background, motivation, and social support could explain student attitudes towards math. In their paper, they adapted the "Intrinsic Motivation Inventory" to assess main determinants of self-motivation. They also measured the teacher's perception, peer support, and student attitude. In their findings, students held positive attitude towards mathematics, and this attitude explained their grade achievements in mathematics. They further conducted a hierarchical analysis using SEM which showed that motivation-related variables are the main predictors of student attitude and that teachers and peer support are highly significant in explaining these attitudes. Their findings tie in perfectly with the findings of Khayati and Payan [4] whose work dwelt on the opinions of teachers on the factors that influence students' interest in mathematics. In their findings, separation of educational classroom of mathematics from the main classroom, peers, size and appearance of math book, and first-grade teachers in each educational level, among whom the elementary first-grade teachers had more importance and impact, were among the most influential and important factors in this regard. They further added that school environment, family, conducting research related to mathematics, its daily application in life and other courses, and studying the history of mathematics were categorized as important factors that would increase the students' interest in mathematics, of which I think that these factors can be categorized into [3] Maria's variables.

Singh et al. [5] used structural equation models to also estimate and test the conjectured relationships of 2 motivation factors, 1 attitude factor, and 1 academic engagement factor, on achievement in mathematics and science among students in the United States. Their results supported the positive effects of the 2 motivation factors, attitude and academic time, on mathematics and science achievement. The strongest effects were those of academic time spent on homework. Davadas and Lay [6] also investigated "Factors Affecting Students' Attitude toward Mathematics: A Structural Equation Modelling Approach" among Malaysian form four students. Using the partial least squares structural equation modeling approach, they established interrelationships between the factors-parental influence, teacher affective support, and classroom attitude-and students' attitude to mathematics. In order, their study found that the 2 latter factors have more influence on students' attitude towards mathematics than the former. Their findings from this study tallies with the findings of Birgin et al. [7] who carried out a study involving 220 Turkish students and found that the enjoyment of the teaching method and help with mathematics from parents has a significant negative effect on mathematics anxiety. Kocakaya and Kocakaya [8] studied how the number of teachers and expert teachers of elementary students has influence on their academic achievements in science and mathematics. They sampled 5,672 elementary students for their study, and using SEM, it has been observed that the established model has acceptable fit indices and an increasing number of teachers and expert teachers have positive effects on students' science and mathematics achievements. Can these positive effects on these 5,672 students' academic achievement in mathematics and science be attributed to an increase in students' interest for mathematics?

Heinze et al. [9] concluded in their work that interest in mathematics could be regarded a predictor for mathematics achievement. They moreover added that students show hardly any fear of mathematics independent of their achievement level; Köller et al. [10] said their data show that interest does not influence achievement in lower secondary schools but it later becomes an important predictor of course choices.

According to Adeyanju [11], "most studies in education focused on what goes on in the classroom while neglecting other important factors such as the sociopsychological factors. He also added that the way an individual learns is not only affected by classroom work and events, but there are other factors which determine what, why, and how individual learns." He added that "the combination of proximal and distal factors ought to be considered but little or no consideration is given to the distal factors like the sociopsychological variables such as self-concept, study habit, attitude, dialect, gender, home and family types, peer group, parental socioeconomic status, and others which exert dominant influence on all facets of life of an individual." How firm are these submissions? Also Akinboye [12] claimed that some factors that influence academic performance of students are heredity, environment, and time. Some factors he added are also resident in the student, the family, the school, and the society. Those factors resident in the student include physical health, truancy, emotional problem, personality factors, poor study habit, self-concept, continued failure, lack of basic cognitive skills, and examination strategies or restiveness. Self-concept is concerned with all that an individual thinks he is, what he thinks he can do, and how best he can do it. According to Hassan [13] and Gbore [14], it is a sort of self-perception, which can be high (positive) or low (negative).

A substantial body of research has accumulated in the last 2 decades works that have examined the correlation between success in academic achievement in general and mathematics and science in particular. Attitudinal and affective variables such as self-concept, confidence in learning mathematics and science, mathematics and 
TABLE 1: Codes for questionnaire items.

\begin{tabular}{|c|c|c|}
\hline Construct & Variable code & 12 \\
\hline \multirow{5}{*}{ Interest (I) } & I1 & \multirow{5}{*}{$\begin{array}{l}\text { Mathematics is an interesting subject to me. } \\
\text { I prefer doing mathematics to other subjects. } \\
\text { Solving mathematics problems require too much } \\
\text { thinking. } \\
\text { I use my leisure time to study mathematics. } \\
\text { Mathematics is useful only to those learning } \\
\text { mathematics as major. }\end{array}$} \\
\hline & I5 & \\
\hline & $\mathrm{I} 23$ & \\
\hline & $\mathrm{I} 27$ & \\
\hline & I30 & \\
\hline \multirow{5}{*}{ Confidence (C) } & $\mathrm{C} 21$ & \multirow{5}{*}{$\begin{array}{l}\text { Mathematical knowledge enables me to think } \\
\text { logically. } \\
\text { I am confident in learning mathematics. } \\
\text { I can easily follow mathematics lessons. } \\
\text { I am good at using mathematics to solve problems. } \\
\text { I feel good in learning mathematics. }\end{array}$} \\
\hline & $\mathrm{C} 25$ & \\
\hline & $\mathrm{C} 28$ & \\
\hline & $\mathrm{C} 32$ & \\
\hline & $\mathrm{C} 36$ & \\
\hline \multirow{5}{*}{ Motivation (M) } & M11 & \multirow{5}{*}{$\begin{array}{c}\text { I often learn mathematics on my own. } \\
\text { I feel less encouraged to learn mathematics. } \\
\text { I often desire for knowledge in mathematics. } \\
\text { I would like to develop myself further in learning } \\
\text { mathematics. } \\
\text { Learning has developed my reasoning ability. }\end{array}$} \\
\hline & M13 & \\
\hline & M16 & \\
\hline & M37 & \\
\hline & M38 & \\
\hline \multirow{5}{*}{ Anxiety (A) } & A8 & \multirow{5}{*}{$\begin{array}{l}\text { I do not feel comfortable during mathematics } \\
\text { periods. } \\
\text { Mathematics is a very difficult subject. } \\
\text { I feel bored during mathematics lessons. } \\
\text { I have always tried to avoid mathematics in my life. } \\
\text { I wish I do not meet mathematics any more during } \\
\text { my further studies. }\end{array}$} \\
\hline & A14 & \\
\hline & A18 & \\
\hline & A31 & \\
\hline & A38 & \\
\hline \multirow{5}{*}{ Usefulness (U) } & U12 & \multirow{5}{*}{$\begin{array}{l}\text { Mathematics is not an important subject. } \\
\text { I do not use mathematics in everyday life. } \\
\text { Knowledge in mathematics helps me to learn other } \\
\text { subjects. } \\
\text { Mathematical knowledge is needed to solve almost all } \\
\text { life problems. } \\
\text { Mathematics knowledge is useful to all students } \\
\text { irrespective of the programme of study. }\end{array}$} \\
\hline & U15 & \\
\hline & $\mathrm{U} 24$ & \\
\hline & U33 & \\
\hline & U35 & \\
\hline
\end{tabular}

TABle 2: KMO and Bartlett's test.

\begin{tabular}{lcc}
\hline & KMO and Bartlett's test & \\
\hline Kaiser-Meyer-Olkin measure of sampling adequacy & & 0.737 \\
Bartlett's test of sphericity & Approx. chi-square & 36442.277 \\
& Df & 3321 \\
& Sig. & 0.000 \\
\hline
\end{tabular}

science interest and motivation, and self-efficacy have emerged as salient predictors of achievement in mathematics and science. These factors also predict mathematics and science avoidance on the part of students, which affects long-term achievement and career aspirations in the mathematics/science field.

In our study, we use a very unique approach by introducing variables that have not been examined by earlier researchers; we investigate how math anxiety, its usefulness, the confidence of the student, and student motivation affect their interest in mathematics. This study will inform the educational institutions on these variables in the formation of students' interest.
1.2. Study Area. The research was done in the Brong-Ahafo Region of Ghana. The region's demography includes the following details: there are 57 public senior high schools (SHS) in the region. A little over two fifths of the population (42.0\%) aged six and older have never been to school. The proportion of the population that has attained primary $(22.3 \%)$ and middle or JHS (23.3\%) is almost the same; only $11.2 \%$ have attained SHS level or higher. The education attainment is the same for males and females at the preschool level (1.2\% each) and the primary school level $(22.5 \%$ males and $22.0 \%$ females). Beyond these two attainment levels, male attainment is higher than that of females at each subsequent level. This low attainment level for females has 
TABLE 3: Rotated component matrix.

\begin{tabular}{|c|c|c|c|c|c|}
\hline \multirow{2}{*}{ Variables } & \multicolumn{5}{|c|}{ Component } \\
\hline & 1 & 2 & 3 & 4 & 5 \\
\hline I1 & 0.704 & & & & \\
\hline I5 & 0.636 & & & & \\
\hline $\mathrm{I} 23$ & 0.631 & & & & \\
\hline $\mathrm{I} 27$ & 0.606 & & & & \\
\hline $\mathrm{I} 30$ & 0.59 & & & & \\
\hline $\mathrm{C} 21$ & & 0.712 & & & \\
\hline $\mathrm{C} 25$ & & 0.701 & & & \\
\hline $\mathrm{C} 28$ & & 0.673 & & & \\
\hline C32 & & 0.658 & & & \\
\hline $\mathrm{C} 36$ & & 0.65 & & & \\
\hline M11 & & & 0.619 & & \\
\hline M13 & & & 0.604 & & \\
\hline M16 & & & 0.6 & & \\
\hline M37 & & & 0.549 & & \\
\hline M38 & & & 0.504 & & \\
\hline A8 & & & & 0.575 & \\
\hline A14 & & & & 0.568 & \\
\hline A18 & & & & 0.556 & \\
\hline A31 & & & & 0.549 & \\
\hline A34 & & & & 0.482 & \\
\hline U12 & & & & & 0.615 \\
\hline U15 & & & & & 0.606 \\
\hline $\mathrm{U} 24$ & & & & & 0.599 \\
\hline U33 & & & & & 0.552 \\
\hline U35 & & & & & 0.517 \\
\hline
\end{tabular}

Extraction method: principal component analysis. Rotation method: varimax with Kaiser normalization. Rotation converged in 6 iterations.

TABLE 4: Reliability statistics.

\begin{tabular}{lcc}
\hline Construct & Cronbach's alpha & Number of items \\
\hline Interest & 0.802 & 5 \\
Confidence & 0.792 & 5 \\
Motivation & 0.783 & 5 \\
Anxiety & 0.797 & 5 \\
Usefulness & 0.753 & 5 \\
\hline
\end{tabular}

implication for the economic characteristics of the population as well as fertility behaviour.

\section{Methodology}

2.1. Population. Senior high schools in the Brong-Ahafo Region of Ghana constitute the population. The sample of the study includes 275 SHS students from the Brong-Ahafo Region. To promote the generalizability of results from the sample to the population, at least one SHS in each district in the region was chosen for study.

2.2. Procedure. The most important features of scientific studies include measuring and relating variables and revealing causality (if any). However, observable variables such as the students' age, programme of study, and sex can be directly measured, while latent variables such as anxiety, usefulness, confidence, motivation, and interest cannot be directly measured. In such cases, it is important to establish
TABLE 5: Regression weights for the conceptualized path model.

\begin{tabular}{|c|c|c|c|c|}
\hline Relationships & Estimate & SE & CR & $P$ \\
\hline Confidence $\longleftarrow$ usefulness & 0.800 & 0.179 & 4.471 & 0.001 \\
\hline Confidence $\longleftarrow$ anxiety & & 0.086 & & 0.002 \\
\hline Motivation $\longleftarrow$ anxiety & -0.090 & 0.058 & -1.542 & 0.123 \\
\hline Motivation $\longleftarrow$ usefulness & 0.587 & 0.149 & 3.952 & 0.001 \\
\hline Motivation $\longleftarrow$ confidence & 0.372 & 0.099 & 3.773 & 0.001 \\
\hline Interest $\longleftarrow$ confidence & 0.801 & 148 & 5.399 & 0.001 \\
\hline Interest $\longleftarrow$ motivation & & 0.136 & 1.065 & 0.287 \\
\hline SN1I $\longleftarrow$ interest & & 0.110 & 7.040 & 0.001 \\
\hline SN5I $\longleftarrow$ interest & 0.8 & 112 & 7.162 & 0.001 \\
\hline SN23I $\longleftarrow$ interest & & .112 & 8.198 & 0.001 \\
\hline SN27I $\longleftarrow$ interest & 0.713 & 0.115 & 6.200 & 0.001 \\
\hline SN30I $\longleftarrow$ interest & 1.000 & & & \\
\hline $\mathrm{SN} 38 \mathrm{M} \longleftarrow$ moti & 0.763 & 0.148 & 5.145 & 0.001 \\
\hline SN37M $\longleftarrow$ motiva & 0.93 & 160 & 5.857 & 0.001 \\
\hline $\mathrm{SN} 16 \mathrm{M} \longleftarrow$ motiva & 0.7 & 0.145 & 5.245 & 0.001 \\
\hline $\mathrm{SN} 13 \mathrm{M} \longleftarrow$ motivation & -0.233 & 0.132 & -1.760 & 0.078 \\
\hline $\mathrm{SN} 11 \mathrm{M} \longleftarrow$ motivation & 1.000 & & & \\
\hline SN36C $\longleftarrow$ confidence & 0.872 & 0.125 & 6.991 & 0.001 \\
\hline $\mathrm{SN} 32 \mathrm{C} \longleftarrow \mathrm{co}$ & & 0.114 & 5.893 & 0.001 \\
\hline SN28C $\longleftarrow$ confidence & 0.698 & 0.111 & 6.275 & 0.001 \\
\hline SN25C $\longleftarrow$ confidence & 1.000 & & & \\
\hline SN21C $\longleftarrow$ confidence & 0.897 & 0.130 & 6.906 & 0.001 \\
\hline $\mathrm{A} \longleftarrow$ an & & 0.138 & 5.805 & 0.001 \\
\hline $\mathrm{SN} 31 \mathrm{~A} \longleftarrow$ anxiety & 0.848 & 0.144 & 5.905 & 0.001 \\
\hline SN31A $\longleftarrow$ anxiety & 1.000 & & & \\
\hline $\mathrm{SN} 14 \mathrm{~A} \longleftarrow$ anxiety & 0.692 & 0.130 & 5.333 & 0.001 \\
\hline SN8A $\longleftarrow$ anxiety & 0.817 & 0.136 & 5.988 & 0.001 \\
\hline SN35U $\longleftarrow$ usefulness & 0.995 & 0.167 & 5.944 & 0.001 \\
\hline SN33U $\longleftarrow$ usefulness & 1.000 & & & \\
\hline $\mathrm{SN} 24 \mathrm{U} \longleftarrow$ usefulness & 0.993 & 0.161 & 6.174 & 0.001 \\
\hline SN15U $\longleftarrow$ usefulness & -0.305 & 0.162 & -1.883 & 0.060 \\
\hline SN12U $\longleftarrow$ usefulness & 0.005 & 0.174 & 0.027 & 0.979 \\
\hline
\end{tabular}

TABLE 6: Fit indices concerning the conceptualized path model.

\begin{tabular}{lcc}
\hline Fit indices & Calculated value & Acceptable range of values \\
\hline CMIN/DF & 2.484 & Between 2 and 5 \\
GFI & 0.843 & $>0.90$ \\
AGFI & 0.909 & $>0.90$ \\
CFI & 0.927 & $>0.90$ \\
NFI & 0.822 & $>0.90$ \\
RFI & 0.876 & $>0.90$ \\
IFI & 0.933 & $>0.90$ \\
TLI & 0.995 & $>0.90$ \\
RMSEA & 0.071 & $<0.08$ \\
\hline
\end{tabular}

regression equalities that show how endogenous structures (predicted-endogenous) are linked with exogenous structures (predictive-exogenous) [15] and to benefit from a multivariate statistical analysis approach which has a wide usage area in combining measurement principles like the structural equation model (SEM) [16]. SEM is a new and very strong analysis technique which consists of the combination of multivariate statistical techniques and which is used commonly by scientists who are engaged in social sciences, like economists, education, and marketing researchers. SEM is an effective model testing and improving 
TABLE 7: Regression weights for the modified path model.

\begin{tabular}{|c|c|c|c|c|}
\hline Relationships & Estimate & SE & CR & $P$ \\
\hline Confidence $\longleftarrow$ anxiety & -0.321 & 0.094 & -3.402 & $<0.001$ \\
\hline Confidence $\longleftarrow$ usefulness & 0.684 & 0.133 & 5.133 & $<0.001$ \\
\hline Motivation $\longleftarrow$ usefulness & 0.435 & 0.114 & 3.806 & $<0.001$ \\
\hline Motivation $\longleftarrow$ confidence & 0.373 & 0.083 & 4.473 & $<0.001$ \\
\hline Interest $\longleftarrow$ confidence & 0.677 & 0.119 & 5.681 & $<0.001$ \\
\hline Interest $\longleftarrow$ motivation & 0.188 & 0.138 & 1.366 & 0.172 \\
\hline SN1I $\longleftarrow$ interest & 1.000 & & & \\
\hline SN5I $\longleftarrow$ interest & 1.043 & 0.166 & 6.285 & $<0.001$ \\
\hline SN23I $\longleftarrow$ interest & 1.191 & 0.171 & 6.948 & $<0.001$ \\
\hline SN27I $\longleftarrow$ interest & 0.931 & 0.165 & 5.630 & $<0.001$ \\
\hline SN30I $\longleftarrow$ interest & 1.296 & 0.185 & 7.009 & $<0.001$ \\
\hline SN38M $\longleftarrow$ motivation & 1.000 & & & \\
\hline $\mathrm{SN} 37 \mathrm{M} \longleftarrow$ motivation & 1.174 & 0.228 & 5.242 & $<0.001$ \\
\hline SN16M $\longleftarrow$ motivation & 0.988 & 0.206 & 4.788 & $<0.001$ \\
\hline SN11M $\longleftarrow$ motivation & 1.252 & 0.241 & 5.204 & $<0.001$ \\
\hline SN36M $\longleftarrow$ confidence & 1.000 & & & \\
\hline SN32C $\longleftarrow$ confidence & 0.768 & 0.103 & 7.469 & $<0.001$ \\
\hline SN28C $\longleftarrow$ confidence & 0.797 & 0.096 & 8.281 & $<0.001$ \\
\hline $\mathrm{SN} 25 \mathrm{C} \longleftarrow$ confidence & 1.143 & 0.163 & 7.469 & $<0.001$ \\
\hline SN21C $\longleftarrow$ confidence & 1.020 & 0.103 & 9.877 & $<0.001$ \\
\hline $\mathrm{SN} 34 \mathrm{~A} \longleftarrow$ anxiety & 1.000 & & & \\
\hline $\mathrm{SN} 31 \mathrm{~A} \longleftarrow$ anxiety & 1.068 & 0.202 & 5.284 & $<0.001$ \\
\hline SN18A $\longleftarrow$ anxiety & 1.250 & 0.216 & 5.794 & $<0.001$ \\
\hline $\mathrm{SN} 14 \mathrm{~A} \longleftarrow$ anxiety & 0.858 & 0.178 & 4.812 & $<0.001$ \\
\hline SN8A $\longleftarrow$ anxiety & 1.018 & 0.191 & 5.320 & $<0.001$ \\
\hline SN35U $\longleftarrow$ usefulness & 1.000 & & & \\
\hline SN33U $\longleftarrow$ usefulness & 0.989 & 0.167 & 5.917 & $<0.001$ \\
\hline SN24U $\longleftarrow$ usefulness & 0.999 & 0.157 & 6.379 & $<0.001$ \\
\hline
\end{tabular}

method that enables theoretical models to be tested as a whole and that can explain the cause and effect relationship of the variables in mixed hypotheses which are related to the models based on statistical dependence. It is based on the testing of a model of the relations among the variables that stands in the researcher's mind before the research is done, via data acquired from the research [17]. Being a prolongation of general regression analysis, which makes more than one regression analysis at a time, SEM can be used in testing traditional models. But, differently, it is a useful method also in situations where more complicated relations (confirmatory factor analysis, time series, etc.) emerge [18]. The working areas are theoretic structures that are represented by latent variables. Basically, it is the combination of factor analysis and regression analysis. It scrutinizes the suitability of the estimated covariance matrix, which is composed, according to the theoretical structure, of the covariance matrix of observed data [19]. SEM, while resembling the regression analysis mostly, is a very powerful statistical technique that models interactions, can cope with nonlinear situations, allows correlation among independent variables, includes measurement errors in the model, regards measurement errors which have correlation among themselves, and exposes and tests the relations among multiple independent and dependent latent variables, each of which is measured with more than one observed variable. While other multivariate statistical methods have exploratory and descriptive features, SEM presents a confirmatory structure. And, this reveals the superior sides of SEM in hypothesis
TABLE 8: Standardized regression weights.

\begin{tabular}{|c|c|c|c|}
\hline & Estimate & $\mathrm{CR}$ & AVE \\
\hline SN1I $\longleftarrow$ interest & 0.476 & \multirow{5}{*}{0.857} & \multirow{5}{*}{0.720} \\
\hline SN5I $\longleftarrow$ interest & 0.489 & & \\
\hline SN23I $\longleftarrow$ interest & 0.580 & & \\
\hline SN27I $\longleftarrow$ interest & 0.414 & & \\
\hline SN30I $\longleftarrow$ interest & 0.589 & & \\
\hline SN38M $\longleftarrow$ motivation & 0.325 & \multirow{4}{*}{0.846} & \multirow{4}{*}{0.630} \\
\hline SN37M $\longleftarrow$ motivation & 0.382 & & \\
\hline SN16M $\longleftarrow$ motivation & 0.331 & & \\
\hline SN11M $\longleftarrow$ motivation & 0.392 & & \\
\hline SN36C $\longleftarrow$ confidence & 0.680 & \multirow{5}{*}{0.891} & \multirow{5}{*}{0.761} \\
\hline SN32C $\longleftarrow$ confidence & 0.483 & & \\
\hline SN28C $\longleftarrow$ confidence & 0.539 & & \\
\hline SN25C $\longleftarrow$ confidence & 0.452 & & \\
\hline SN21C $\longleftarrow$ confidence & 0.655 & & \\
\hline SN34A $\longleftarrow$ anxiety & 0.485 & \multirow{5}{*}{0.847} & \multirow{5}{*}{0.665} \\
\hline SN31A $\longleftarrow$ anxiety & 0.503 & & \\
\hline SN18A $\longleftarrow$ anxiety & 0.662 & & \\
\hline $\mathrm{SN} 14 \mathrm{~A} \longleftarrow$ anxiety & 0.427 & & \\
\hline SN8A $\longleftarrow$ anxiety & 0.510 & & \\
\hline SN35U $\longleftarrow$ usefulness & 0.547 & \multirow{3}{*}{0.996} & \multirow{3}{*}{0.985} \\
\hline SN33U $\longleftarrow$ usefulness & 0.514 & & \\
\hline SN24U $\longleftarrow$ usefulness & 0.591 & & \\
\hline
\end{tabular}

TABle 9: Fit indices concerning the modified path model.

\begin{tabular}{lcc}
\hline Fit indices & Calculated value & Acceptable range of values \\
\hline CMIN/DF & 2.027 & Between 2 and 5 \\
GFI & 0.989 & $>0.90$ \\
AGFI & 0.962 & $>0.90$ \\
CFI & 0.936 & $>0.90$ \\
NFI & 0.926 & $>0.90$ \\
RFI & 0.988 & $>0.90$ \\
IFI & 0.939 & $>0.90$ \\
TLI & 0.913 & $>0.90$ \\
RMSEA & 0.059 & $<0.10$ \\
\hline
\end{tabular}

testing. Moreover, while the other kinds of multivariate statistics cannot determine and correct measurement errors, SEM includes almost all the measurement parameters and comes to the conclusion according to [20]. Because of the reasons explained above, it is thought that working with SEM, which is an analysis method that can measure the stated variables more comprehensively, significantly, and reliably, will contribute to the literature.

2.3. Model Construction. In this study, students' confidence and motivation were conceptualized to have a direct effect on their interest in mathematics, whilst anxiety and usefulness of mathematics were conceptualized to have indirect effects on their interest in mathematics, moderated by confidence and motivation. Therefore, by setting the model given in Figure 1, whether the model fits the collected data was tested and the effects of anxiety, usefulness, confidence, and motivation on students' interest in mathematics were examined in the model. 


\section{Results and Discussion}

3.1. Factor Analysis. In Table 1, a code is dedicated to each questionnaire item which is used in tagging the items for subsequent analysis. Based on literature review, the main constructs considered in this study include interest, confidence, motivation, anxiety, and usefulness.

The Kaiser-Meyer-Olkin (KMO) test is used to measure the adequacy of a sample. KMO test numbers are between 0 and 1 . Zero means that the sum of correlations for parts of them are large in comparison with the sum of all correlations, so factor analysis is likely inappropriate. Kaiser suggests that values greater than 0.5 are acceptable. For this study, we observe from Table 2 that the KMO is 0.737 which is acceptable.

Bartlett's test measure whether or not an original correlation matrix is an identity matrix. If a matrix is an identity matrix, all correlation numbers would be zero. From Table 2, Bartlett's test of sphericity is highly significant at 0.05 level.

After extracting standard components and rotating them to normalize them, loaded indicators to them were conducted by factor analysis as the main part of exploratory factor analysis. Table 3 illustrates the number of loaded items in the rotated component matrix. Using varimax rotation, the focus is on fitting each indicator to one construct (factor). Thus, loadings which are less than 0.4 are suppressed by our criteria in SPSS.

According to the rotated component matrix in Table 3, loaded numbers are sorted by size, so they are not in order of questions. Items for interest dimension are loaded in component 1 , items related to confidence are loaded in component 2 , items on motivation are loaded in component 3 , items on anxiety are loaded in component 4 , and items on usefulness are loaded in component 5. Several items recorded loadings below 0.4 and were not considered in building the structural equation model.

3.2. Reliability Analysis. Reliability analysis is conducted using Cronbach's alpha coefficient for internal consistency. The results are summarised in Table 4. The coefficients for interest, confidence, motivation, anxiety, and usefulness are $0.802,0.792,0.783,0.797$, and 0.753 , respectively. In summary, the reliability coefficients for the five constructs employed in this study exceed the minimum threshold value of 0.7 suggested by [21] Nunnally (1978).

3.3. SEM Findings. In Figure 2, the effects (direct and indirect) between the variables in the conceptualized model are given. The reason SEM is superior to ordinary regression and correlation analysis is that we can actually see indirect latent effects. The effects (regression weights) and their statistical significance are given in Table 1.

We observe from Table 5 that confidence of a student has the biggest $(0.801, P<0.001)$ direct effect on his/her interest in mathematics. Also, anxiety and students' perception of the usefulness of mathematics affect his confidence and motivation directly in studying mathematics. However, like the effect of anxiety on motivation, the effect of students' motivation on their interest in mathematics was not significant. It is also observed from Table 5 that some items had negative correlations with their constructs. For example, SN13M and SN15U had negative correlations $(-0.233$ and -0.305 ) with their respective constructs (motivation and usefulness). Hence, these items were dropped in a modification of the conceptual path model.

Several model fit indices were used to evaluate how good the conceptual model fits the collected data. The calculated values and the range of acceptable values for these indices are given in Table 2. We observe from the table that GFI, NFI, and RFI do not fall in the range of acceptable values. This suggests that the conceptual path model may not be a good fit to the collected data which may be as a result of the negative correlations we observed between some of the items and their constructs.

Details of the fit indices are found in the following literature: for CMIN/DF, see Marsh and Hocevar [20]; for RMSEA, see Browne et al. [22]; for NFI, GFI, AGFI, and CFI, see Byrne [23] and Jöreskog and Sörbom [24]; for TLI, see Bentler and Bonett [25]; for IFI, see Bollen [26]; and for RFI, see Bollen [27].

After dropping the items that had negative correlations with their constructs, the resulting modified path model is shown in Figure 3.

In Figure 4, the effects (direct and indirect) between the variables in the modified model are given. The effects (regression weights) and their statistical significance are given in Table 6.

We observe from Table 7 that confidence of a student still had the biggest $(0.677, P<0.001)$ direct effect on his/her interest in mathematics. Also, anxiety and students' perception of the usefulness of mathematics still affect their confidence and motivation directly in studying mathematics. However, the effect of students' motivation on their interest in mathematics was still not significant.

Table 8 has in it the standardized regression weights and their respective composite reliability (CR) and average variance extracted (AVE). The CR and AVE values exceed the minimum threshold value of 0.7 and 0.5 (Hair et al. [28]), respectively. The values calculated for CR and AVE were from 5 items for the variables interest and confidence, 4 items for the variable anxiety, and 3 items for usefulness. The fitted model is therefore significant considering the CR and AVE values.

A look at the values of the goodness-of-fit indices in Table 9 clearly reveals that all indices are within the acceptable range of values. This indicates that the modified path model is a good fit to the collected data.

\section{Conclusion}

In this study, the effects of students' confidence and motivation on their interest in mathematics are examined and having the variables, mathematics anxiety and the students' knowledge, on the usefulness of mathematics conceptualized to have indirect effects on students' interest. This study is conjectured on the hypotheses that confidence and motivation have influence on students' interest and also, 
mathematics anxiety and students' knowledge on mathematics' usefulness has an indirect influence on students' interest.

We observe from our study that confidence of a student has the biggest $(0.677, P<0.001)$ direct effect on his interest in mathematics. Also, anxiety-just as reported by Anigbo and Idigo [29] - and students' perception of the usefulness of mathematics affect their confidence and motivation directly in studying mathematics.

However, the effect of students' motivation on their interest in mathematics was still not significant. Our findings disagree with the study of Musso et al. [3] whose SEM showed that motivational-related variables are the main predictors of attitudes towards mathematics.

Confidence directly affects students' interest in the learning of mathematics, and there is a direct relationship between confidence and motivation. Also, students' motivation to study mathematics depends largely on their knowledge of the usefulness of mathematics. A students' knowledge of the usefulness of mathematics also modifies his/her confidence level in pursuing mathematics. The perception on the usefulness of mathematics affects students' confidence level. While a good knowledge of the usefulness of mathematics increases the confidence level in students, the lack of confidence among students in learning mathematics leads to anxiety among students.

The teaching of mathematics should be geared towards making students understand and see the usefulness of mathematics. Mathematics teachers should therefore introduce students to real-world application of mathematics to increase their knowledge of its usefulness that would indirectly increase their interest in mathematics by directly fuelling their confidence and motivation to learn mathematics.

\section{Data Availability}

The data used to support the findings of this study are available from the corresponding author upon request.

\section{Conflicts of Interest}

The authors declare that there are no conflicts of interest regarding the publication of this paper.

\section{References}

[1] S. Hidi and J. M. Harackiewicz, "Motivating the academically unmotivated: a critical issue for the 21st century," Review of Educational Research, vol. 70, no. 2, pp. 151-179, 2000.

[2] https://www.collinsdictionary.com/dictionary/english/ interest.

[3] M. Musso, E. Kyndt, E. Cascallar, and F. Dochy, "Predicting mathematical performance: the effect of cognitive processes and self-regulation factors," Education Research International, vol. 2012, Article ID 250719, 13 pages, 2012.

[4] S. Khayati and A. Payan, "Effective factors increasing the students' interest in mathematics in the opinion of mathematic teachers of Zahedan," World Academy of Science, Engineering and Technology International Journal of Social,
Behavioral, Educational, Economic, Business and Industrial Engineering, vol. 8, no. 9, pp. 3069-3077, 2014.

[5] K. Singh, M. Granville, and S. Dika, "Mathematics and science achievement: effects of motivation, interest, and academic engagement," Journal of Educational Research, vol. 95, no. 6, pp. 323-332, 2002.

[6] S. D. Davadas and Y. F. Lay, "Factors affecting students' attitude toward mathematics: a structural equation modeling approach," Eurasia Journal of Mathematics, Science and Technology Education, vol. 14, no. 1, pp. 517-529, 2017.

[7] O. Birgin, M. Baloğlu, H. Çatlığlu, and R. Gürbüz, “An investigation of mathematics anxiety among sixth through eighth grade students in Turkey," Learning and Individual Differences, vol. 20, no. 6, pp. 654-658, 2010.

[8] S. Kocakaya and F. Kocakaya, "A structural equation modeling on factors of how experienced teachers affect the students' science and mathematics achievements," Education Research International, pp. 1-8, 2014.

[9] A. Heinze, K. Reiss, and R. Franziska, "Mathematics achievement and interest in mathematics from a differential perspective," Zentralblatt für Didaktik der Mathematik, vol. 37, no. 3, pp. 212-220, 2005.

[10] O. Köller, J. Baumert, and K. Schnabel, “Does interest matter? The relationship between academic interest and achievement in mathematics," Journal for Research in Mathematics Education, vol. 32, no. 5, pp. 448-470, 2001.

[11] P. F. Adeyanju, "Self-concept, study habits and academic performance in school studies among secondary school students in Oyo State," Ph.D. thesis, University of Ado-Ekiti, Ado-Ekiti, Nigeria, 2006.

[12] J. O. Akinboye, How to Study and Pass Important Examination. A Psychological Approach, Maritime Printers, Ibadan, Nigeria, 1980.

[13] E. M. Hassan, “Anxiety, self concept and academic performance differential b/n single double parents students in Oyo State," Nigerian Journal of Counselling Applied psychology, vol. 2, no. 1, pp. 29-39, 2004.

[14] L. O. Gbore, Cognitive Entry characteristic, study Habits and self-concept as predictors of academic performance of University under graduate, Ph.D. thesis, University of Ado-Ekiti, Ado Ekiti, Nigeria, 2006.

[15] V. Yilmaz, H. E. Celik, and E. H. Ekiz, "Investigation of the factors that affect the authority's commitment with structural equation modelling; a sample of bank of primary and government," Journal of Social Sciences, vol. 2, pp. 171-184, 2006.

[16] J. H. Hair, R. L. Tatham, and R. E. Anderson, Multivariate Data Analysis, Prentice Hall International, New York, NY, USA, 5th edition, 1998.

[17] Information Technology Services, Structural Equation Modelling Using AMOS: An Introduction, 2004, http://www.utexas. edu/its/rc/tutorials/stat/amos/.

[18] J. J. Hox and T. M. Bechger, "An introduction to structural equation modeling," Family Science Review, vol. 11, pp. 354-373, 1995.

[19] J. G. Anderson, The Basic of Structural Equation Model, 2004, http://web.ics.purdue.edu/?janders1/assets/pdf/ SOC681StructuralEquationModelsSyllabus2011.pdf.

[20] H. W. Marsh and D. Hocevar, "Application of confirmatory factor analysis to the study of self-concept. First- and higher order factor models and their invariance across groups," Psychological Bulletin, vol. 97, no. 3, pp. 562-582, 1985.

[21] J. C. Nunnally and I. H. Bernstein, Psychometric Theory, McGraw-Hill New York Google Scholar, New York, NY, USA, 1978. 
[22] M. W. Browne, R. Cudeck, K. A. Bollen, and J. S. Long, "Alternative ways of assessing model fit," in Testing Structural Equation Models, K. A. Bollen and J. S. Long, Eds., pp. 136162, Sage, Newsbury Park, CA, USA, 1993.

[23] B. M. Byrne, Structural Equation Modeling with EQS and EQS/ Windows, Sage, Thousand Oaks, CA, USA, 1994.

[24] K. G. Jöreskog and D. Sörbom, LISREL 7 Users Reference Guide, SPSS Publications, Chicago, IL, USA, 1989.

[25] P. M. Bentler and D. G. Bonett, "Significance tests and goodness of fit in the analysis of covariance structures," Psychological Bulletin, vol. 88, no. 3, pp. 588-606, 1980.

[26] K. A. Bollen, "A new incremental fit index for general structural equation models," Sociological Methods and Research, vol. 17, pp. 303-316, 1989.

[27] K. A. Bollen, "Sample size and bentler and Bonetts nonnormed fit index," Psychometrika, vol. 51, no. 3, pp. 375-377, 1986.

[28] J. F. Hair, R. E. Anderson, R. L. Tatham, and W. C. Black, Multivariate Data Analysis, Prentice-Hall lnc., Upper Saddle River, NJ, USA, 2005.

[29] L. C. Anigbo and E. Idigo, "Factors affecting students' interest in mathematics in secondary schools in enugu state," Journal of Science and Computer Education, vol. 3, no. 3, 2015. 


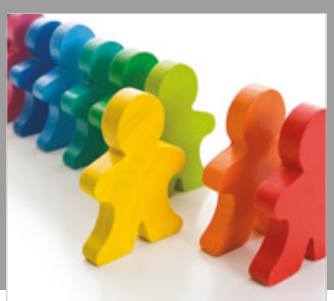

Autism

Research and Treatment
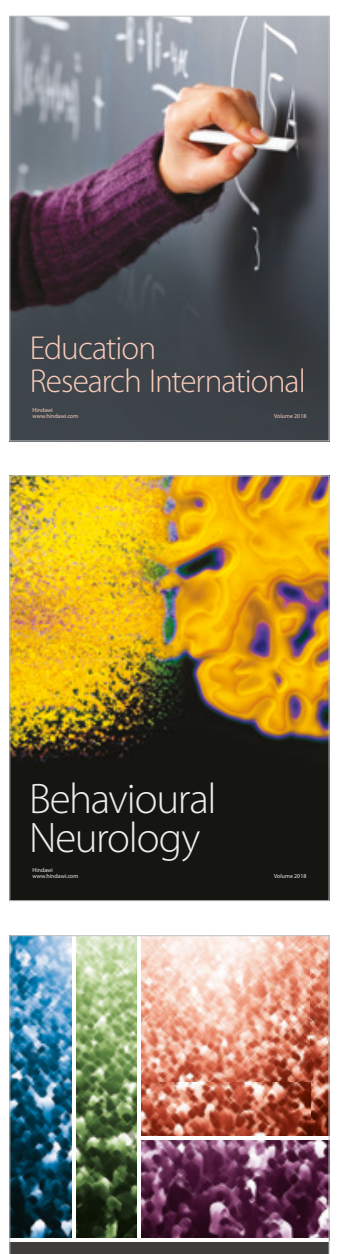

International Journal of

Population Research

$\underline{-m}$

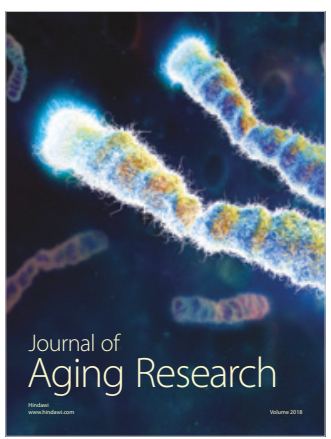

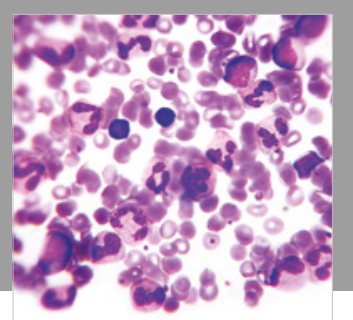

Pathology

Research International$$
=
$$

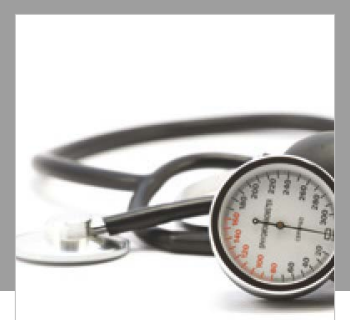

Nursing

Research and Practice

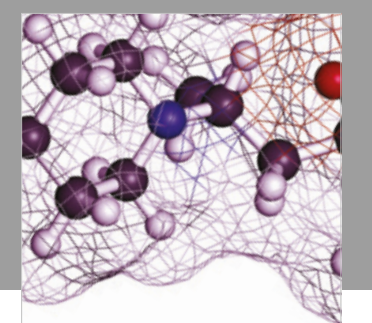

Pain

Research and Management

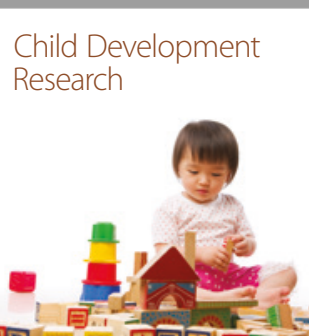

बाD

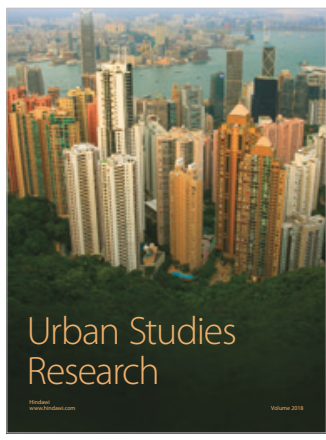

\section{Hindawi}

Submit your manuscripts at

www.hindawi.com
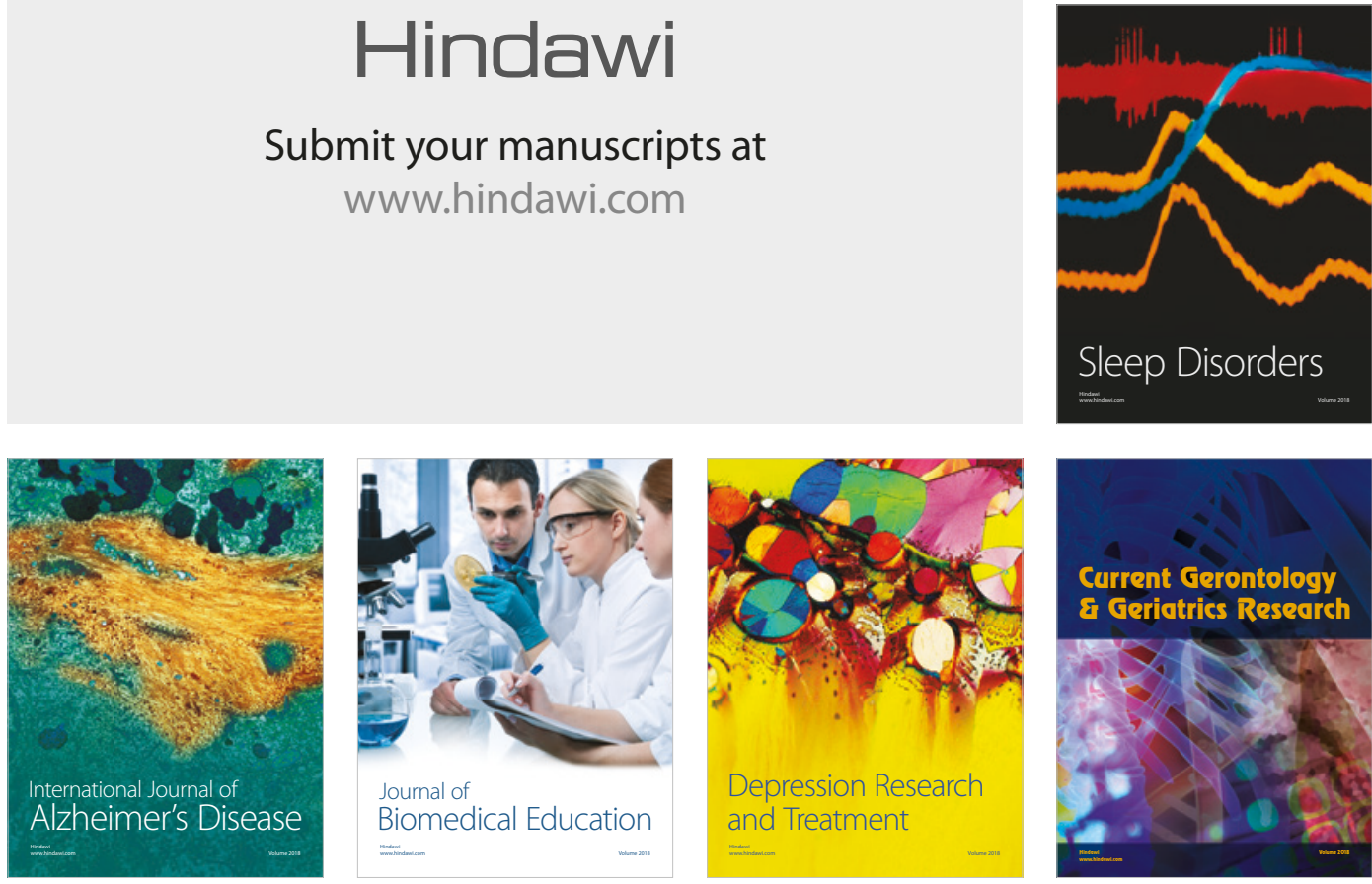

Journal of

Biomedical Education

$=$

smman

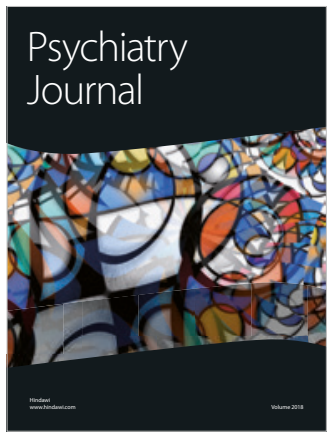

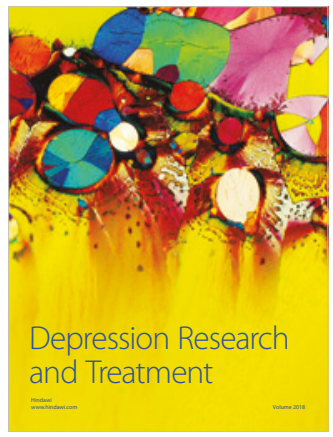
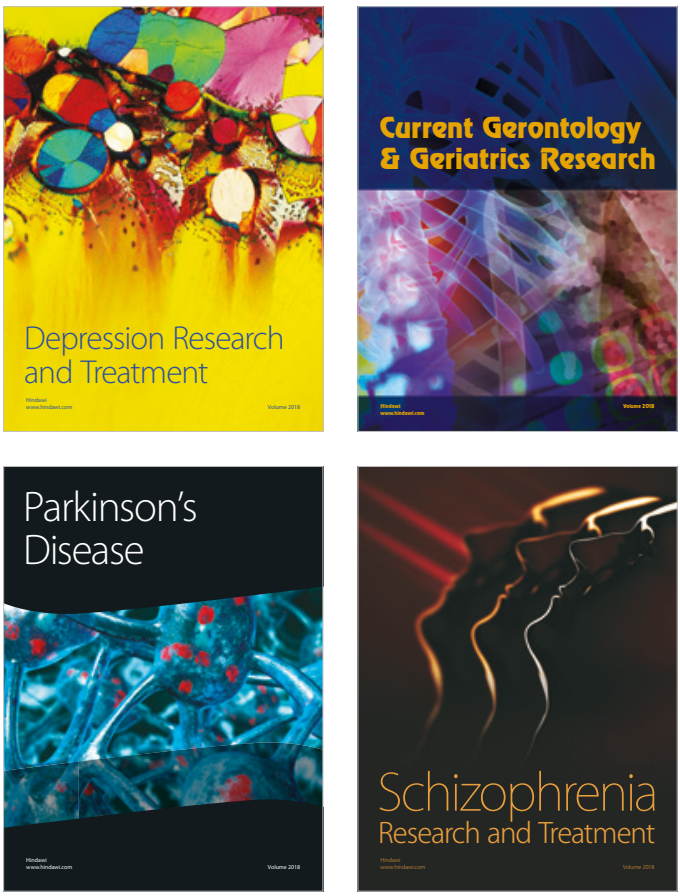